\title{
Solar Panel Analysis for Human Activity Monitoring System
}

\author{
Nyayu Latifah Husni ${ }^{1}$, Putri Adelia Rahma Sari ${ }^{1}$, Ade Silvia Handayani ${ }^{1, *}$, \\ Yeni Irdayanti ${ }^{1}$ A. Rakhman ${ }^{1}$, Hairul Hairul ${ }^{1}$, Seyed Amin Hosseini Seno ${ }^{2}$ \\ Wahyu Caesarendra ${ }^{3}$
}

\author{
${ }^{1}$ State Polytechnic of Sriwijaya \\ ${ }^{2}$ Ferdowsi University of Mashhad, Iran \\ ${ }^{3}$ Universiti Brunei Darussalam \\ ${ }^{*}$ Corresponding author. Email: ade_silvia@polsri.ac.id
}

\begin{abstract}
The infrastructure development is not equal to the consciousness of keeping it. In many areas, the destruction occurs before the development has been finished. One of them can be seen in Sekanak River restoration. Some parts have been damaged although the development has still be in progress. Therefore, an activity monitoring system that can monitor and give warning to the vandal is really needed. The system can be an alternative to prevent more destructions. However, due to the system will be applied in the public areas that is difficult to be reachable by the electrical source from the State Electricity Company, an independent supply is needed. This paper presents an analysis of the solar panel that can supply the system continuously. The analysis involves the calculation of the supply that can be used to switch on the system for 24 hours a day. From the experimental setting, it can be proved that the proposed solar panel design and construction has worked well. It can supply the total need of the system power of 200 watt for 24 hours.
\end{abstract}

Keywords: Infrastructure Development, Activity Monitoring, Sekanak River, Restoration, Destruction, Solar Panel.

\section{INTRODUCTION}

The development of technology and renewable energy is growing rapidly every year. One of them is the progress and developments of several infrastructures. However, all infrastructure that has been constructed by the government is still not really taken care. Sometimes, they have been damaged and have became the places for littering. Therefore, decisive action, such as making warning system that can warn the community not to littering is needed.

The infrastructure will be watched directly by the monitoring systems. It is no need to watch the destructive activity using guard anymore. This system will not only useful for monitoring the surround activities but also to make the infrastructure cleaner and free of waste. In this research, the activity monitoring system is equipped with solar panels as the source. Solar, as a form of renewable energy, offers many advantages. It is safe, reliable, efficient, non-polluting, and it can be widely distributed. Solar energy, particularly photovoltaic (PV) technology, has become a hot topic of global interest [1]. It is the same like other sources of energy (i.e., renewable energy and fossil fuel sources), solar energy utilization has some environmental concerns. Solar and wind energies are non-thermal renewables which do not use water for drycooling systems. Therefore, they have very low operational water-use intensities. It is different with solar panels, some PV systems need a relatively small amount of water for washing panels [2]. In many application, they obtained water directly from the rain. Thus, they have no need to be supplied by the water.

The monitoring system in this research will utilize solar energy. It is due to solar energy is the largest energy and will not run out. This energy will be converted into electrical energy by using solar panels that function as converter of this energy. It can operate properly and can reduce environmental air pollution. The application of solar panels in this activity monitoring system will give some benefits, such as its simplicity in use. The placement of the monitoring system in the public, of course, will face difficulty in getting the source. To get 
a power source from the state electricity company is quite difficult. It need a long and complicated cabling system. Thus, the use of solar energy becomes good solution.

The solar energy will be very helpful in operating the proposed human activity monitoring system. This monitoring system will detect and monitor the environmental destruction conducted by human. In addition, it can also detect environmental conditions, such as temperature, humidity, air quality, and water level. It is intended to maintain the infrastructure that has been constructed by the government. Based on the importance of the monitoring system for helping in maintaining the infrastructure, therefore the use of solar panel become essential. However, how to design and analyse the solar panels that will be used are still a problem. Therefore, in this paper, the calculation of the solar panels used in the activity monitoring system is presented. It is intended to get a good performance of the solar energy system. It should be able to work for 24 hours and it should be able to overcome the energy waste and the high cost of solar energy system.

\section{METHODOLOGY}

The block diagram of activity monitoring system in this research can be seen in Figure 1.

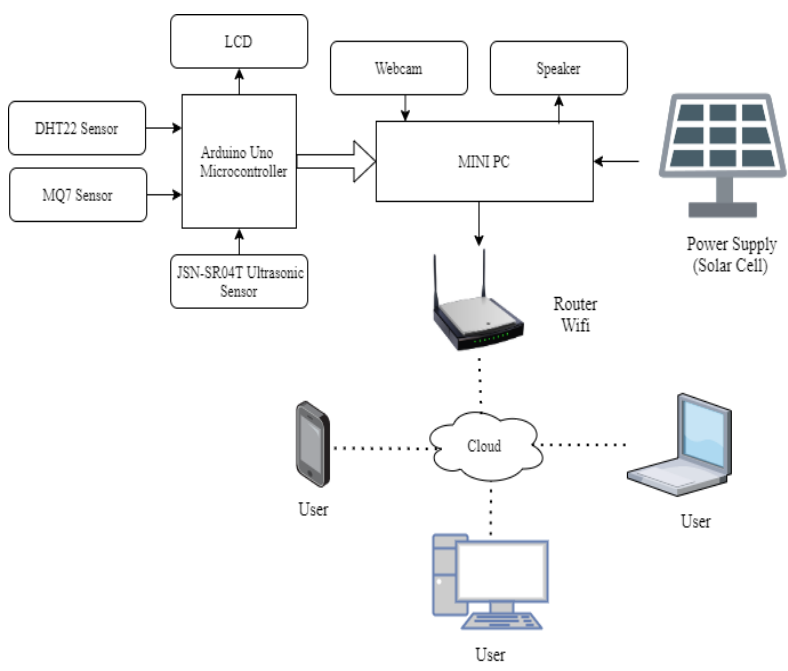

Figure 1 Solar Panel connection in Activity Monitoring System at Sekanak River

Based on Figure 1, there are some important components used, such as the DHT 22 sensor that has function as ambient temperature and humidity detector, MQ7 as a CO gas detector, and a Waterproof Ultrasonic Sensor that has function to detect the water level of the Sekanak river. All input components of this system will get a power source from the solar panel, i.e., by connecting the Mini PC to the solar panel. The system should be able to operate for 24 hours in order to keep the monitoring device on continuously. The output of the system can be accessed via the internet.

Solar energy in this research is composed by several components, such as: batteries as a source and storage of electric power, MCB batteries, SCC (Solar Charge Controller), inverter, LVD, and MCB Panels. In the process of using solar panels in this activity monitoring system, calculations are carried out on the required use in detail to avoid wasting costs and unused components.

The solar panels in this activity monitoring system are placed in 2 places, namely the Sekanak River and 27 Ilir mini garden that are located in Palembang. The block diagram of the mini garden monitoring system can be seen in Figure 2. The solar panel is used to supply the energy to the components shown in Figure 2.

Basically, the components connection in mini garden is the same with the Sekanak river, however, in Sekanak mini garden, the ultrasonic sensor is not needed.

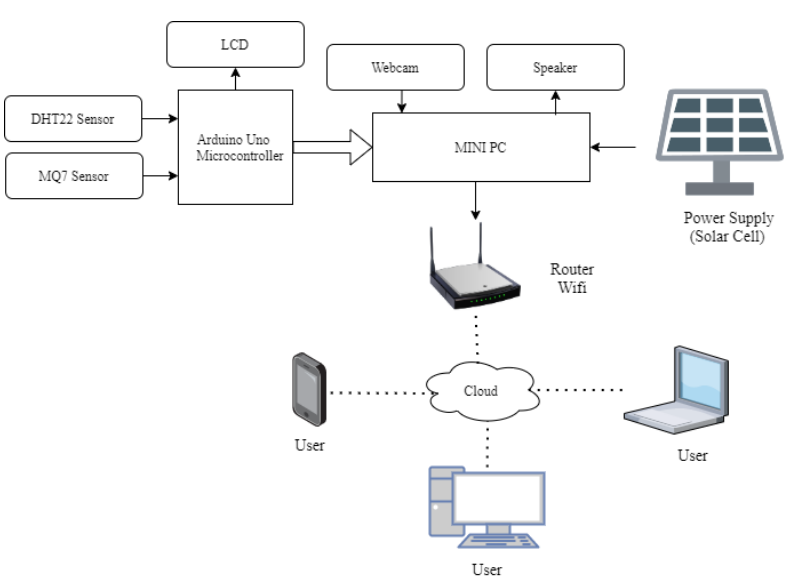

Figure 2 Solar Panel connection in Activity Monitoring System at 27 Ilir Mini Garden

\section{METHODOLOGY}

\subsection{Collecting Data}

This research method is carried out by collecting data, namely:

a. Study Literature

In the study of literature, the authors seek and study references from various sources or theories related to this research, such as books, journals, articles, and other websites from the internet.

b. Observation

After the authors searched and studied from various sources, the authors collected data by making direct observations to calculate the needs of 
solar panels in the activity monitoring system. After that, the authors formulate and analyze the result

\subsection{System Design}

Planning includes most of the steps to carry out the analysis process of solar panels on activity monitoring systems. Flowchart of planning and designing tools can be seen in the Figure 3

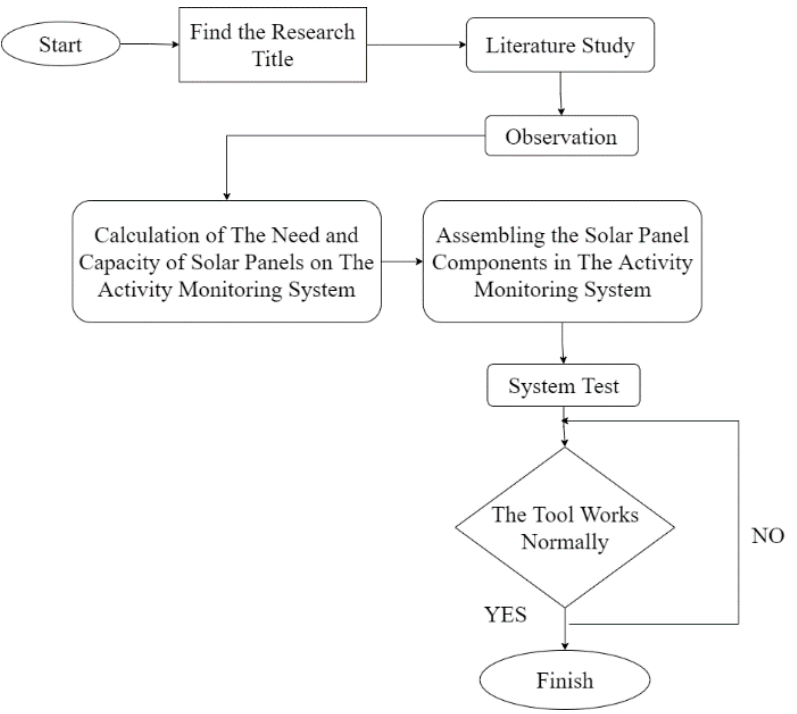

Figure 3. Design of the system

\subsection{Calculation of solar panel capacity and needs.}

The calculation is needed to determine the capacity of the solar panel required. Actually, it mostly depends on the need of the energy for running the activity monitoring system. The design of the circuit system can be used as the reference to determine what should be prepared at the beginning of the project.

The required components of the solar system, include:

1. Solar panels

2. Battery/Accu

3. SCC (Solar Charge Controller)

4. MCB Battery

5. MCB Panel

6. MCB Inverter

7. Inverters

8. LVD (Low Voltage Disconnect)

However, the user needs not only to consider the components above but also to determine the casing of the components that should be used. In this case, the casing should be able to cover all of the components. It should pay attention to the a tidiness of the system. In this research, all of the components is stored and connected in the electrical boxes as in Figure 4.

\subsubsection{Assembling the Solar Panel components}

After the components provided are already prepared, the next step is to assembly the components so that it can be put well in the electrical box. Then, the testing can take place.

\subsubsection{System Testing}

After the system assembling is complete, the performance of the system will be tested. In testing the system, it is needed to measure the output voltage generated from solar cells. This can be done by using a solar charge controller MPPT (maximum power point tracking) and PWM (Pulse width Modulation).

The testing should also conduct to the battery used in solar panels. This battery has a capacity of 200 watts and it is supported by an inverter with a capacity of 100 watts. If the system testing does not operate well, then it will return to the system planning process as shown in Figure 3. If the system can operate properly, it will proceed to the system analysis process.

\subsubsection{Analysis}

This section shows the analysis of the calculating process of the solar panels needed. The calculation can be done by performing the calculations on 1 part of the solar panel and calculation of the battery used.

Total power generated can be calculated using equation (1)

$$
\begin{array}{ll}
\text { Power } & =200 \mathrm{~W} \\
& =200 \mathrm{wh}: 60 \% \\
& =333.33 \mathrm{w} \\
\text { Total power } & =334 \text { watts }
\end{array}
$$

Thus, solar panel requirement can be calculated as shown in equation (2)

Solar panels $\quad=$ total power: optimal time

$$
=334 \mathrm{w}: 4 \text { hours }(2)
$$




$$
\begin{aligned}
& =83.5 \text { watts peak } \\
& \approx 100 \mathrm{WP}
\end{aligned}
$$

For example, the system uses 1 solar panel and 2 solar panels

1 piece of solar panel is $100 \mathrm{WP}$

$$
\begin{aligned}
& =100 \mathrm{WP} \times 4 \text { hours } \\
& =400 \mathrm{~W}
\end{aligned}
$$

2 pieces of solar panels using $50 \mathrm{WP}$

$$
\begin{aligned}
& =50 \mathrm{WP} \times 2 \\
& =100 \mathrm{WP} \\
& =100 \mathrm{WP} \times 4 \text { hours } \\
& =400 \mathrm{WP}
\end{aligned}
$$

Then the battery used can be in the form of:

1. If 1 battery is used,

$$
\begin{aligned}
1 \text { Battery } & =12 \mathrm{~V} \times 30 \mathrm{Ah} \\
& =360 \mathrm{WH}
\end{aligned}
$$

2. If 2 batteries are used

$$
\begin{aligned}
2 \text { Batteries } & =(12 \mathrm{v} \times 15 \mathrm{Ah}) 2 \mathrm{pcs} \\
& =360 \mathrm{WH}
\end{aligned}
$$

Based on the results of the above calculations, the use of 1 piece of solar panel that uses $100 \mathrm{WP}$ should be divided by $60 \%$. It is due to the solar panel energy is not $100 \%$ obtained. There will be wasted load of $\pm 40 \%$.

The advantage of using only 1 piece is that the cable used is not too complicated. However, it has also drawback, such as if the panel is damaged, the system will stop and electricity cannot be produced.

If the system uses 2 pieces of solar panels, in which each chip has $50 \mathrm{WP}$, there will be an advantage. When one of the panels is damaged, the other panel can still produce electricity in parallel. However, the drawback is that it needs a lot of space

In the process of using 2 batteries, there will be 2 ways in the installation process, namely series, and parallel. In series, the required voltage for the battery is 24 volts while the current is $15 \mathrm{Ah}$. However, if installed in parallel, the required voltage is 12 volts, and the current is $30 \mathrm{Ah}$.

\subsection{System Planning}

The flow of power or voltage generated by the solar panel in the system proposed in this research, is set on the solar charge controller which is used to control the charging of the battery.
Solar Charge Controller serves to protect the battery against overcharge so that the possibility of battery damage can be minimized. After the battery is charged, the inverter can be used to convert the DC voltage to AC so that it can operate the activity monitoring system.

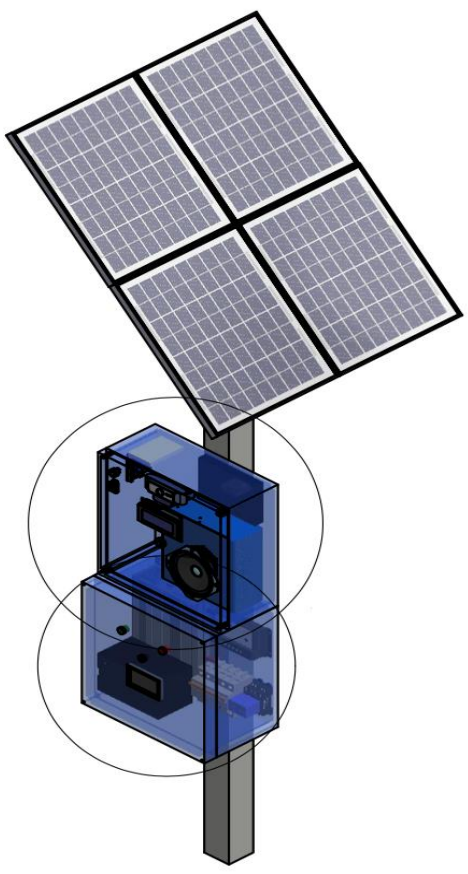

Figure 4. Design of the Solar Panel construction for Activity Monitoring System.

The design of the solar panel construction is shon in Figure 4. The power or voltage generated by the solar panels cannot operate the load directly. Solar panel energy will be stored first in the battery (battery) then used for load operation. The existence of a battery can make the system be able to operate a load, The load performance is generally more influenced by the condition of the battery compared to the amount of radiation received by the solar panel.

\subsection{Working Principle}

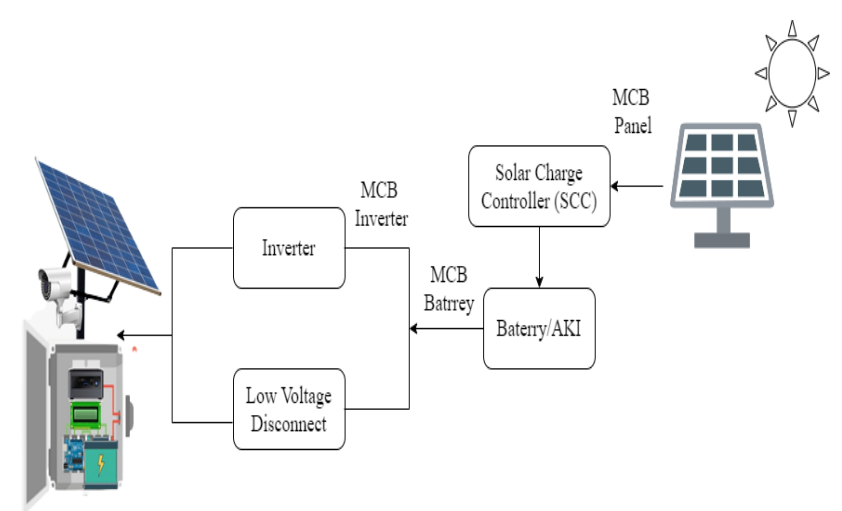

Figure 5 The Working Principle of Solar Panels on Activity Monitoring Systems. 
Based on Figure 5, The solar panel has an electrical box that functions as a place for attaching the inverter, solar charge controller, LVD and other components. In the solar panel electrical box, there is a battery that is used as the source and as the storage of electrical power that has been obtained from the solar panel. This battery is connected to the MCB battery to avoid a short circuit in the battery. Then, the solar panel will be connected to the MCB panel as a protective device and insulator (electrical circuit breaker) from excessive current surges from the DC power grid system generated by the solar panels. In addition, there is an SCC or Solar Charge Controller to optimize the system and maintain battery life. It is then then connected to the MCB Inverter that functions to convert the current.

As a breaker from the solar panel to the controller, from the controller to the battery, from the battery to the inverter, and from the controller to the inverter, it is used the LVD or Low Voltage Disconnect as a protective device that serves to protect the battery from damage due to over-discharge. The LVD will disconnect the battery load automatically if the battery voltage is down and it will reconnect the load automatically if the battery is recharged.

\section{CONCLUSIONS}

To use power, the sun must consider and plan carefully and check the minimum requirement of the electrical energy required before investing in the system of solar power generator. This is meant to avoid purchasing of inappropriate components with need. Considering the price, the initial investment in this power generation system relatively expensive.

\section{REFERENCES}

[1] Y. Xu, J. Li, Q. Tan, A. L. Peters, and C. Yang, "Global status of recycling waste solar panels: A review," Waste Manag., vol. 75, pp. 450-458, 2018, doi: 10.1016/j.wasman.2018.01.036.

[2] A. Shahsavari and M. Akbari, "Potential of solar energy in developing countries for reducing energy-related emissions," Renew. Sustain. Energy Rev., vol. 90, no. March, pp. 275-291, 2018, doi: 10.1016/j.rser.2018.03.065.

[3] C. A. Grant and A. L. Hicks, "Effect of manufacturing and installation location on environmental impact payback time of solar power," Clean Technol. Environ. Policy, vol. 22, no. 1, pp. 187-196, 2020, doi: 10.1007/s10098019-01776-z.

[4] A. Kumari, J. Patra, N. Pal, and N. Kumar, "Impact of Solar Panel on the Transformer
Performance: A Case Study," Iran. J. Sci. Technol. - Trans. Electr. Eng., vol. 44, no. 3, pp. 1197-1206, 2020, doi: 10.1007/s40998-01900300-9.

[5] T. Gerarden, "Demanding Innovation: The Impact of Consumer Subsidies on Solar Panel Production Costs," no. May 2018, pp. 18-77, 2018, [Online]. Available: https://scholar.harvard.edu/files/gerarden/files/g erarden_jmp.pdf.

[6] B. P. Jelle, "The challenge of removing snow downfall on photovoltaic solar cell roofs in order to maximize solar energy efficiency - Research opportunities for the future," Energy Build., vol. 67, no. 7465, pp. 334-351, 2013, doi: 10.1016/j.enbuild.2013.08.010.

[7] K. Ranabhat, L. Patrikeev, A. A. evna Revina, K. Andrianov, V. Lapshinsky, and E. Sofronova, "An introduction to solar cell technology," $J$. Appl. Eng. Sci., vol. 14, no. 4, pp. 481-491, 2016, doi: 10.5937/jaes14-10879.

[8] R. Yue and T. Ying, "A water quality monitoring system based on wireless sensor network \& solar power supply," 2011 IEEE Int. Conf. Cyber Technol. Autom. Control. Intell. Syst. CYBER 2011, pp. 126-129, 2011, doi: 10.1109/CYBER.2011.6011777.

[9] A. S. Spanias, "Spanias2017,” pp. 18-21, 2017.

[10] L. Xu, X. Ruan, C. Mao, B. Zhang, and Y. Luo, "An improved optimal sizing method for windsolar-battery hybrid power system," IEEE Trans. Sustain. Energy, vol. 4, no. 3, pp. 774-785, 2013, doi: 10.1109/TSTE.2012.2228509.

[11] F. Fauzi, M. F. N. Tajudin, M. F. Mohamed, A. Azmi, and N. A. A. Manaf, "Assessment of inhouse build low cost solar panel simulator," $J$. Phys. Conf. Ser., vol. 1878, no. 1, 2021, doi 10.1088/1742-6596/1878/1/012038.

[12] S. Koushik and V. Sandeep, "Design and Selection of Solar Powered Off-Board Domestic Charging Station for Electric Vehicles," 2021 Int. Conf. Sustain. Energy Futur. Electr. Transp. SeFet 2021, pp. 3-8, 2021, doi 10.1109/SeFet48154.2021.9375758.

[13] N. R. Moheimani and D. Parlevliet, "Sustainable solar energy conversion to chemical and electrical energy," Renew. Sustain. Energy Rev., vol. 27, pp. 494-504, 2013, doi: 10.1016/j.rser.2013.07.006.

[14] A. Arora and A. Gambardella, The Globalization of the Software Industry: Perspectives and Opportunities for Developed and Developing Countries, vol. 5. 2005 